\title{
Educar para quê? Observações acerca da educação e cultura a partir do pensamento de Friedrich Nietzsche
}

\author{
Luciana da Costa Dias
}

\section{Resumo}

O presente artigo tem por objetivo discutir a relação entre cultura e educação em Friedrich Nietzsche, filósofo conhecido pelo caráter intempestivo de seus escritos e profundo crítico de sua época. Sua abordagem da questão da educação é, na verdade, um profundo questionamento da própria função e propósito da prática educativa, que ele diagnosticou como estando, já em sua época, cada vez mais submissa e atrelada aos interesses de uma economia de mercado, mero adestramento e preparação para o mercado de trabalho, uma vez que seu discurso se constrói com base em uma visão extremamente crítica ao surgimento do ensino profissionalizante, naquele período, na Alemanha.

Palavras-chave: Filosofia alemã. Filosofia da educação. Friedrich Nietzsche.

\section{Introdução}

O objetivo deste artigo é discutir a relação entre cultura e educação tendo como pano de fundo, sobretudo, a obra III Consideração intempestiva: Schopenhauer educador, escrita em 1874 por Friedrich Nietzsche, publicada no Brasil, pela primeira vez, em 2003. Nesse sentido, mais do que apenas fazer uma exposição sistemática e pontual desse texto, pretende-se explorar e discutir a problemática proposta, conforme ela se desdobra a partir da obra citada e com as necessárias pontes com outros textos e elementos presentes à obra de Nietzsche, vistos em perspectiva, na medida em que eles podem ser necessários à plena discussão da questão.

\author{
Recebido: 15/01/2016 - Aprovado: 24/05/2016 \\ http://dx.doi.org/10.5335/rep.v23i2.6542
}

\begin{abstract}
Doutora em Filosofia pela Universidade do Estado do Rio de Janeiro. Professora adjunta de Teoria da Arte e Estética Teatral no Departamento de Artes Cênicas, no Programa de Pós-Graduação em Artes Cênicas e no Programa de Pós-Graduação em Filosofia da Arte e Estética do Instituto de Filosofia, Artes e Cultura da Universidade Federal de Ouro Preto. E-mail: lucianacdias@yahoo.com.br
\end{abstract}


Para alcançar tal objetivo, serão apresentadas, inicialmente, as críticas de Nietzsche à educação e à cultura (consideradas decadentes) de sua época para, a partir daí, desdobrar o que o autor entende por educação e cultura autênticas, as quais, como se irá investigar, detêm estreita relação com a afirmação da vida, mesmo em suas contradições - questão que será mais tarde desenvolvida com vigor na obra nietzschiana -, chegando-se assim ao papel de "mestre" e à "homenagem" que Nietzsche presta a Schopenhauer nesse texto, com uma discussão de qual seria o verdadeiro sentido dessa.

\section{A crítica de Nietzsche à educação e à cultura}

A crítica de Nietzsche à educação e à cultura de sua época insere-se em um panorama maior de mudanças, que estava se processando na Alemanha desde meados do século XVIII, não só de alterações políticas (como a unificação dos vários estados alemães), mas também da crescente modernização e industrialização da Alemanha (tardias em relação ao processo de industrialização da França e da Inglaterra), que, somadas à ascensão da burguesia, significavam drásticas mudanças políticas, econômicas e culturais para esse povo. Até então, como destaca Marton (1993), a cultura e a educação inseriam-se no contexto do idealismo alemão, que valorizava os autores, modelos e ideais clássicos, garantindo o caráter de criação desinteressada, desligada de intenções utilitárias. Esse caráter perder-se-ia, e a educação adquiriu, progressivamente, um caráter instrumental e prático, voltado para o crescente mercado de trabalho.

Tem-se que a abordagem da questão da educação é, na verdade, um profundo questionamento da própria função e do propósito da prática educativa, que Nietzsche diagnosticou como estando, já em sua época, cada vez mais submissa e atrelada aos interesses de uma economia de mercado, mero adestramento e preparação para o mercado de trabalho, uma vez que seu discurso se constrói com base em uma visão extremamente crítica ao surgimento do ensino profissionalizante na Alemanha do período.

Contudo, pode-se observar que as mudanças que Nietzsche critica não ocorreram só na Alemanha, mas caracterizam a história moderna da educação como um todo. Também não se trata de um fenômeno restrito àquela época, posto ter prosseguido em diferentes reconfigurações, até resultar no atual modelo fragmentário de disciplinas, nas quais, na maior parte das vezes, o estudante não consegue ver nexo, o que potencializa a relevância da crítica nietzschiana.

A cultura hoje seria o agrupamento de caprichos momentâneos, moda, opinião pública e cultura jornalística. É a propalada cultura de massa "fabricada" pela 
Indústria cultural, um meio em que os homens "estudam" para "aprender a ganhar dinheiro" e ganham dinheiro para consumir, mantendo o sistema em movimento, muitas vezes para consumir os "bens culturais", pois até a cultura parece ser um grande comércio. Do mesmo modo, o ensino, que não mais visava à formação integral do homem (que seria aquela na esteira da afirmação nietzschiana da idealidade da cultura grega e que, por pretender retomar os valores "clássicos", intenciona formar homens cultos, capazes de exercitar de maneira clara e harmoniosa todas as suas potencialidades), passou a ser tão somente ensino profissionalizante (FRAGOSO, 1974).

São essas transformações, que Nietzsche constata já em sua época, que conduzem a importantes mudanças não só no conceito de cultura socialmente apregoado como também no modelo de educação considerado ideal, defendido e então implementado pelo Estado.

Nietzsche (2003c) aponta, em Sobre o futuro de nossos estabelecimentos de ensino, escrito pouco antes da III Intempestiva, em 1872, um quadro peculiar na Alemanha de sua época: a crença amplamente difundida da necessidade e possibilidade de uma "cultura geral" - que, para Nietzsche, não detém valor genuíno, pois não passa de agrupamento de superficialidades, como uma "cultura jornalística" - versus a realidade de miséria cultural existente, empreendida a partir da redução das escolas a "centros profissionalizantes" e das universidades a "centros especializados".

No sexto item da III Consideração intempestiva: Schopenhauer educador, Nietzsche (2003b) afirma que, em sua época - que ainda é a nossa época, no sentido de que, como destacaria Heidegge, a época atual é ainda a consumação da era moderna, o acirramento de sua problemática (2000) -, duas coisas se opõem à verdadeira cultura, à cultura autêntica: o "egoísmo dos negociantes" e o "egoísmo do Estado". Esses são os grandes responsáveis pela transformação da cultura em mera cultura utilitarista, um misto de bem de consumo com formação para o trabalho, que é a formação moderna do jovem, que apresenta apenas dois objetivos ligados entre si: educar para ganhar dinheiro, porque é o dinheiro, e nada mais, que trará felicidade, e formar para trabalhar, para adequar o jovem aos meios de produção, integrando-os às instituições já existentes e conformando-os à sociedade vigente.

A crítica de Nietzsche mostra-se assertiva. Como podem os interesses do Estado configurarem a cultura? Para Nietzsche, cultura genuína e Estado caminham em lados opostos. Em sua época (e ainda na nossa), o critério de avaliação da cultura (dos "bens culturais") torna-se o critério das necessidades do consumidor, a cultura paulatinamente transforma-se em um produto a ser consumido. A ponto de 
a formação de um jovem, que antes era voltada para uma cultura autêntica - isto é, entendida como cultivo de si, como formativa e integralizadora das potencialidades individuais de cada um -, passar à mera capacitação para ganhar dinheiro, arrumar um emprego, assumir seu lugar no mecanismo social, satisfazer as necessidades do rebanho.

Desse modo, a educação a serviço do Estado não é mais que um instrumento de manutenção do status quo vigente, a formar cidadãos dóceis para o mercado. Essa é a educação propalada nos estabelecimentos de ensino de sua época, comparada por Nietzsche a um "processo de mediocrização universal". Os atuais estabelecimentos de ensino pecariam por sua "pobreza de espírito pedagógico", ao formarem alunos em massa, não atentando para sua formação individual.

A assim chamada "cultura geral" moderna seria aquela em que se sabe um pouco de tudo e acaba-se por não saber nada ou, ainda, sabe-se muito de uma parcela tão ínfima do real que se perde a noção do todo. Para Nietzsche, seria não mais que uma 'barbárie cultivada' (termo que a Escola de Frankfurt depois se apropriará).

Mas será somente tal cultivo da barbárie que se pode esperar da educação e da cultura? Em texto anterior, de 1874, chamado II Consideração intempestiva: da utilidade e desvantagem da história para a vida, Nietzsche (2003a) já demonstrara como a História precisa estar sempre "a serviço da vida", sendo mais do que um "monumento" inútil ao que passou. Pois, se a história traz em si a possibilidade de ser útil para a vida, também traz a possibilidade de debilitá-la em sua dinâmica originária, se a acorrenta (CASANOVA, 2003).

Isso também se aplica à cultura e à educação, embora possam ser um entrave empobrecedor da vida (como no caso da era moderna), também podem ser um elemento potencializador da própria vida, esse sim um objetivo a ser perseguido - e é essa possibilidade que constitui, segundo Nietzsche, a raiz de toda cultura e educação "autênticas". "Que a vida seja o valor máximo!" será o mote perseguido por Nietzsche em suas obras futuras (KLOSSOWSKI, 2000).

\section{A possibilidade de cultura e educação autênticas}

A cultura autêntica é, para Nietzsche, a de inspiração "clássica", visando à formação de espíritos-livres - um espírito tão livre talvez quanto virá a ser Zaratustra, na obra de Nietzsche (MACHADO, 1999). A cultura verdadeira é, então, necessariamente aristocrática, mas não no sentido usual e pérfido do termo. A cultura dos melhores não tem a ver com classe social, mas, sim, com a perspectiva de visar à formação dos melhores: uma cultura de seres-humanos fortes, que plenamente 
desenvolvam suas potencialidades, algo que não pode ser alcançado nem por meio da erudição microscópica do especialista nem atrelado à pura formação de "profissionais" para meramente disputarem uma vaga no mercado de trabalho. A cultura autêntica tem de estar necessariamente para além das necessidades econômicas e/ ou de subsistência, antes devendo visar à formação integral do homem.

Um dos aspectos que inicialmente saltam aos olhos ao se ler os textos de Nietzsche sobre educação é o fato de que educação nunca é um projeto grupal ou para as massas. Mas, por quê? Porque é um projeto individual. A educação como cultivo de si é de difícil alcance porque seria uma educação independente de padrões e métodos únicos largamente aplicáveis, mas, ao contrário, mostra-se como um processo individual, trabalhoso, um caminho para cada um.

O início da III Consideração intempestiva: Schopenhauer educador é de uma beleza atroz, como no momento em que Nietzsche afirma: “[...] todo homem é um milagre irrepetível” (2003b, p. 138). Mas, apesar de ser um milagre irrepetível, muitas vezes, o homem é mais inclinado ao medo de seus semelhantes e ao pudor de se assumir como único, em um comportamento autoamputante. A educação como cultivo de si mostra-se como algo impensável para as massas em sua "propensão ao comodismo", uma vez que Nietzsche destaca o comodismo e a preguiça como a característica também marcante dos seres humanos. Poucos seriam os indivíduos capazes de se destacar do "rebanho" e de querer buscar uma educação autêntica para si. O comodismo e a preguiça seriam o que faz os homens não buscarem o pleno cultivo de si, mas, simplesmente, adequarem-se aos padrões, mantendo e perpetuando isso que Nietzsche denomina de "consciência de rebanho", em vez de admitir o caráter único da própria existência e de suas possibilidades intrínsecas.

A esse respeito, pode-se conferir o trecho a seguir, extraído da II Intempestiva, que se caracteriza pela beleza de suas linhas, não só pela asserção de sua crítica:

Mas ainda que o futuro não nos deixasse qualquer esperança, a singularidade da nossa existência neste momento preciso é o que nos encorajaria mais fortemente a viver segundo a nossa própria lei e conforme a nossa própria medida: quero falar sobre este fato inexplicável de vivermos justamente hoje, quando dispomos da extensão infinita do tempo para nascer, quando não possuímos senão o curto lapso de tempo de um hoje e quando é preciso mostrar nele, por quê razões e para que fins, aparecemos exatamente agora. Temos de assumir diante de nós mesmos a responsabilidade por nossa existência, por conseguinte, temos de agir como os verdadeiros timoneiros desta vida e não permitir que nossa existência pareça uma contingência privada de pensamento. Esta existência, quer que a abordemos com ousadia e também com temeridade, pois no melhor ou no pior dos casos, sempre a perderemos (NIETZSCHE, 2003a, p. 140).

Nesse contexto, pode-se retornar à temática que Michel Haar (2000) vislumbra ao abordar o pensamento nietzschiano: o da vida como obra de arte. $\mathrm{O}$ homem seria, para Nietzsche, a obra de arte que a própria natureza determina e visa a ser 
alcançada, mas que a indústria, o Estado e uma "especialização" podem degenerar e limitar, em vez de conduzir à realização integral. A meta da relação mestre-discípulo é a educação autêntica, que o discípulo também venha se tornar um mestre. A educação como cultivo de si é aquela na qual o homem vê a si mesmo como obra de arte, a ser sempre melhorada e burilada ao longo de toda a sua vida.

Contra a mediocridade da cultura jornalística, Nietzsche busca a possibilidade de uma "vida verdadeiramente artística", no sentido de uma vida plena, afirmativa da vida em sua inteireza trágica. Contra o "animal de rebanho", o da virtude ressentida, apregoada pelo cristianismo, Nietzsche levanta a bandeira do homem solitário, capaz de manter sua autonomia diante dos poderes estabelecidos. Um ponto interessante da III Intempestiva é a ponte que Nietzsche faz entre a falência dos valores cristãos e a impropriedade da cultura moderna:

A que chegou finalmente toda esta reflexão sobre as questões morais, com a qual toda sociedade nobre e evoluída esteve, porém, preocupada em todas as épocas? Não há mais modelos ilustres e não há mais reflexão desse tipo. Vive-se de fato do capital de moralidade acumulado por nossos ancestrais e da herança deles, que não sabemos mais fazer crescer, mas somente dissipar. Na nossa sociedade, ou não se fala absolutamente destas coisas, ou se o faz com um tal acanhamento e uma tal inexperiência de orientação naturalista, que não pode suscitar senão a náusea. Foi assim que nossas escolas e nossos mestres chegaram a fazer simplesmente abstração de qualquer educação moral a se contentar com um puro formalismo; e a virtude é uma palavra com a qual professores e alunos não querem mais pensar nada, uma palavra fora de moda da qual se ri - e 'pior ainda quando não se ri, porque então é a hipocrisia (2003b, p. 145-146).

Acredito que já se pode antever uma prévia de temas que depois o autor abordaria na fase final de seu pensamento, como a crítica aos valores do ocidente por seu caráter "fraco", que aparecerá em livros como Para além do bem e do mal ([1886] 2005) e Genealogia da moral ([1887] 1998), e, ainda mais longe, a crítica ao niilismo como descaminho da cultura ocidental, que se torna ainda mais forte não só em Assim falava Zaratustra ([1885] 1981), mas também no Crepúsculo dos ídolos ([1888] 2006). Pois assim continua Nietzsche:

A explicação desta indolência e da forte estiagem de todas as forças morais é difícil e complicada. Porém, quem quer que leve em consideração a influência do Cristianismo vitorioso sobre a moral do nosso velho mundo, este também não tem absolutamente o direito nem de ignorar a reação do Cristianismo em vias de sucumbir, nem o seu destino cada vez mais visível na nossa época. Pela grandeza moral de seu ideal, o cristianismo ultrapassou os sistemas de moral antigos e o sentimento natural que reina neles uniformemente, tanto que ficou insensível a este natural e achou que ele era repugnante [...]. O ódio hereditário pelo que é natural, e que por outro lado o atrai \{ao homem moderno\}, renovado por este mesmo natural, o desejo de achar um ponto de apoio em algum lugar, a impotência de seu conhecimento que titubeia entre o bem e o melhor, tudo isto engendra uma inquietude, uma confusão na alma moderna, que a condena a ser estéril e sem alegria (2003b, p. 145-146). 
Vemos assim uma primeira relação entre a moral ressentida do cristianismo, sua falência, e o niilismo como única consequência possível à época contemporânea. O niilismo (como Heidegger, sobretudo, interpretará a obra de Nietzsche) é a consequência direta da moral cristã e de sua falência que conduziu o homem moderno à negação do valor da vida. A superação do niilismo e a afirmação da vida como valor máximo é o caminho que conduz o pensamento nietzschiano. Nesse sentido, mesmo sua posição e crítica diante da educação em sua época inscreve-se nesse escopo.

Um ponto que é importante destacar é o de que Nietzsche não opõe natureza e conhecimento, muito menos vida e conhecimento, como usualmente ocorre no pensamento metafísico (com a vida e/ou a natureza sendo inferiorizada). Ao contrário, Nietzsche emparelha educação e natureza, em vez de opô-las ou de subjugar uma à outra. Se no texto Sobre o futuro de nossos estabelecimentos de ensino, Nietzsche (2003c) classifica os métodos atuais de educação como antinaturais, uma educação autêntica seria, ao contrário, a autoafirmação da natureza, como pode ser apreendido da III Intempestiva. A cultura autêntica configura-se, portanto, não como em oposição à natureza, mas como aquilo por meio do qual a physis poderia alcançar sua máxima potência, por intermédio do grande homem, do homem verdadeiro, do gênio, que é, no entender de Nietzsche, essa excrecência da natureza (pois não é o homem, antes de tudo, parte da natureza?), sua verdadeira realização e ponto de culminância. Logo, não deveria ser esse o objetivo de toda cultura autêntica?

Os homens verdadeiros são aqueles que não são mais animais, os filósofos, os artistas e os santos, logo que eles aparecem, com este salto a natureza que jamais dá saltos, dá um salto de alegria [...]. Este é o pensamento fundamental da cultura, na medida em que esta só pode atribuir uma única tarefa a cada um de nós: incentivar o nascimento do filósofo, do artista e do gênio em nós e fora de nós, e trabalhar assim para a realização da Natureza (NIETZSCHE, 2003c, p. 179-180).

É nesse sentido que se pode afirmar que:

[...] o papel da educação é então libertar estas forças interiores que a natureza colocou nos homens para a sua elevação e realização: as forças instintivas e plásticas que permitem a eles realizar suas obras, sobretudo as obras mais elevadas (MELO SOBRINHO, 2003, p. 34).

A educação ideal é aquela capaz de educar o jovem como mais do que mero repositório da cultura de sua época, como alguém capaz de pensar por si mesmo, pensar a própria experiência e criar seus próprios valores e parâmetros. A educação deve ser o caminho para "tornar-se o que se é". Uma cultura autêntica não visa à formação de indivíduos em série, em um processo absolutamente impessoal como nas escolas modernas. Nietzsche defende uma educação individualizada (que conduza ao verdadeiro cultivo de si!), passada de mestre a discípulo em uma relação 
pessoal. Por isso a exacerbação da necessidade de um mestre neste ensaio, colocado por Nietzsche então, em seu caso pessoal, na figura de Schopenhauer.

\section{Schopenhauer educador}

Não podemos esquecer de que a III Intempestiva tem como ponto marcante também a afirmação da necessidade de homens que sirvam de modelo na educação intelectual e moral dos indivíduos - educando-os por meio do exemplo, e não apenas com palavras vazias. Enfim, o problema central é a necessidade de "mestres", no sentido lato da palavra, e não de eruditos, de meros especialistas, palavras que falam de "filosofia", que falam sobre o conhecimento, mas não o "vivem".

Para Nietzsche, Schopenhauer foi um mestre, um exemplo de resistência em sua posição contrária ao hegelianismo, na época em que Hegel dominava os meios acadêmicos alemães. Essa posição seria um dos motivos por Schopenhauer não ter conseguido levar adiante a sonhada carreira acadêmica, tendo vivido como negociante. Schopenhauer conseguiu não perder a "honestidade de não mentir jamais, não mentir para ninguém, não mentir - sobretudo! - para si mesmo" (NIETZSCHE, 2003 b, p. 148). Schopenhauer, como todo gênio, como todo indivíduo que se desvincula do rebanho, esteve sujeito a dois terríveis monstros: solidão e ostracismo. São esses os monstros, os perigos que muitas vezes destroem o indivíduo, impedindo o pleno desenvolvimento de sua genialidade.

Observa-se que essa não deixa de ser uma maneira (velada) de Nietzsche abordar ainda a temática de ser necessário criar instituições que acolham o gênio. Pensar a escola como o lugar que permita à genialidade ser fortalecida e se desenvolver é uma perspectiva assaz desafiadora. Mas, como destaca Nietzsche, seria muito difícil para o gênio viver em meio à turba e suas exigências cotidianas de rebanho:

Nossos Hölderlin e Kleist, e tantos outros, morreram por causa do seu caráter estranho, e não poderiam suportar o clima da pretensa cultura alemã. Somente as naturezas de ferro, como Beethoven, Goethe, Schopenhauer e Wagner, puderam torná-la boa (NIETZSCHE, 2003b, p. 150).

O que se sobressai é a dificuldade, o perigo que os "homens excepcionais enfrentam por viverem numa sociedade demasiadamente ligada à norma ordinária" (NIETZSCHE, 2003b, p. 151). O grande mérito que Nietzsche atribui a Schopenhauer como educador, como modelo inspirador, é sua postura diante de sua época. Schopenhauer revela um caráter intempestivo: é isso que o torna grande. Ele consegue ir além das mazelas de sua época, ser capaz de ir além da tábua de valores 
do próprio tempo, de criar sua própria régua, é isso que o constituiria como "homem superior":

Se de fato preferimos considerar todo grande homem como o verdadeiro filho de seu tempo e como aquele que sofre, em todo caso, com todas as mazelas deste tempo, da maneira mais intensa e com mais sensibilidade do que todos os homens mais medíocres, o combate deste grande homem contra seu tempo só aparentemente é um combate absurdo e destruidor contra si mesmo. Mas isto é somente na aparência, pois, no seu tempo, ele combate o que o impede de ser grande, o que para ele só pode exatamente significar: ser livre e totalmente si mesmo. Segue-se que sua hostilidade é no fundo dirigida contra o que está nele próprio, certamente, mas não é verdadeiramente ele próprio, dirigida contra a mistura impura e confusa de elementos incompatíveis para sempre inconciliáveis, contra a falsa união do atual com seu próprio caráter intempestivo (NIETZSCHE, 2003b, p. 162).

Porém, acerca da relação de Nietzsche com Schopenhauer, algumas observações ainda podem ser feitas. A III Intempestiva encontra-se em um ponto intermediário do pensamento nietzschiano. É interessante ver a junção que Nietzsche já faz entre cultura e vida, embora ainda estivesse apenas começando a assumir a plena afirmação da vida em sua inteireza, como ocorre de forma fremente em sua obra posterior. Como observa Scarlet Marton:

[...] a homenagem que Nietzsche presta aos mestres já tem [então] sabor de despedida. Mais tarde, em sua autobiografia, dirá que quando então falara de Schopenhauer e Wagner [nas Intempestivas], estivera de fato a falar de si mesmo (1993, p. 11).

Nietzsche nesse texto já apresenta indícios de transformar o pessimismo negador da vontade humana de Schopenhauer diante da tragicidade da vida em uma vontade afirmativa da própria vida em sua inteireza, mesmo em seus aspectos mais sombrios. Se, para Schopenhauer, a solução ao caráter trágico da existência foi a negação da vontade, para Nietzsche, era cada vez mais sua afirmação. O pessimismo de Schopenhauer afirma o ceticismo diante da ausência de sentido (metafísico) da existência, de uma vida guiada por uma vontade cega de viver, absurda, desprovida de propósito ou significado, que se revela no mundo somente como carência e dor (MACHADO, 1999).

Ainda que inicialmente tenha compactuado com o pensamento de Schopenhauer, Nietzsche acabaria por não sucumbir ao desespero, à desistência e à negação da vontade individual por ele propostas, antes vindo a afirmar cada vez mais e de forma incondicional a vida - a vida em totalidade, a vida em sua inteireza trágica -, com isso, ultrapassando o conformismo que poderia nascer da constatação do absurdo da vida. Apesar de as diferenças entre o pensamento de Nietzsche e de Schopenhauer não serem ainda tão latentes nos escritos sobre a educação, essas aumentariam cada vez mais com o tempo. Contudo, a questão da estreita relação de uma cultura autêntica estar ligada à construção de si e à afirmação da 
vida é uma temática já subjacente a toda abordagem que Nietzsche realiza acerca da figura de Schopenhauer como educador.

\section{Considerações finais}

Como buscamos alcançar, a discussão sobre a educação empreendida por Nietzsche é, na verdade, um profundo questionamento de própria função e propósito da educação, que ele diagnosticou como estando, em sua época, cada vez mais submissa e atrelada aos interesses de uma economia de mercado, mero adestramento e preparação para o mercado, uma vez que seu discurso se constrói, como procuramos mostrar, com base em uma visão crítica do surgimento do ensino profissionalizante na Alemanha naquele período.

Ainda que a reflexão de Nietzsche pareça ir na contramão de muitas das discussões contemporâneas sobre educação, ainda marcadas em alguma medida por um viés pragmatista e utilitarista, temos de convir que sua reflexão não se exime de pensar as mudanças pelas quais passou (e passa) a educação até suas últimas consequências, inserindo-se no bojo de uma crítica ainda mais dura ao que Nietzsche entende como a raiz da decadência do mundo ocidental.

Se, como coloca Benedito Nunes (2000), a época contemporânea é a personificação da "apatridade do homem" - com a cultura e a educação cada vez mais esfareladas em prol da economia de mercado e de uma "cultura jornalística" -, como não pensar a atualidade de tal questionamento? A assim chamada "cultura da informação", que é a nossa (e informação não é conhecimento, muito menos sabedoria), é hoje em todo lugar disseminada e exaltada, em um ritmo cada vez mais vertiginoso e de forma cada vez mais superficial.

Diante da emergência do que foi chamado de "barbárie cultivada", retroalimentada pelas tecnologias da informação e pelo desenvolvimento de um saber fragmentário, cada vez mais especializado, a educação e seu propósito devem resistir como uma indagação. A crítica realizada por Nietzsche é, "antes de tudo, e no final de contas, uma crítica ao mundo contemporâneo" (LÖWITH, 1969, p. 367) e ao elemento humano que nele pode (ou como pode, de algum modo) se inserir. As críticas de Nietzsche aos estabelecimentos de ensino na Alemanha de sua época mostram-se pertinentes como indagação ainda no Brasil de hoje, posto lidar com características que emergem em todo o mundo ocidental, de um jeito ou de outro, emergindo também em nosso país. E hoje, sobretudo, vemos o sucateamento das instituições públicas de educação trazer à tona o lugar e o propósito da educação como questão cada vez mais urgente. 
Embora Nietzsche afirmasse que "a maior de todas as pretensões é a de querer ser profeta" (2003c, p. 43), é impossível não refletir justamente sobre o oposto dessa afirmação. Ainda que sobrevivam importantes nichos e espaços nas universidades que resistem à redução do ensino e da pesquisa a uma lógica instrumentalizante, vemos, hoje, a comercialização e a compartimentalização da educação ocorrer em níveis ainda mais altos que os de sua época, o que garante a atualidade de suas palavras e a relevância da discussão empreendida por Nietzsche - que se mostra, longe de uma conclusão. Que a educação e os estabelecimentos de ensino possam se manter como lugar de resistência em prol da formação humana para além do mercado: essa é a questão urgente.

\title{
What is the purpose of education? Notes about education and culture from Friedrich Nietzsche's thought
}

\section{Abstract}

\begin{abstract}
This article aims to discuss the relationship between culture and education in Friedrich Nietzsche, a philosopher known by his extemporaneous character of his writings and a deep critic of his own time. His approach to the education matter is truly a profound questioning of function and purpose of educational practice. The problem education is facing is the one he diagnosed as being more and more subjected and linked to market economy's interests, being no more than a mere training or preparation to job market, since his speech is built upon an extremely critical view of the rise of professional education then in Germany.
\end{abstract}

Keywords: German philosophy. Friedrich Nietzsche. Philosophy of education.

\section{Referências}

CASANOVA, M. A. O instante extraordinário: vida, história e valor na obra de Friedrich Nietzsche. Rio de Janeiro: Forense Universitária, 2003.

FRAGOSO, M. X. Nietzsche e a educação. Revista Trans /Form/Ação, Marília, v. 1, p. 277-293, 1974.

HAAR, M. A obra de arte: ensaio sobre a ontologia das obras. Tradução de Maria Helena Kühner. Rio de Janeiro: DIFEL, 2000.

HEIDEGGER, M. Nietzsche: metafísica e niilismo. Tradução de Marco Antônio Casanova. Rio de Janeiro: Relume Dumará, 2000. 
KLOSSOWSKI, P. Nietzsche e o círculo vicioso. Tradução de Hortência S. Lencastre. Rio de Janeiro: Pazulin, 2000.

MACHADO, R. Zaratustra, tragédia nietzscheana. Rio de Janeiro: Jorge Zahar, 1999.

MARTON, S. Nietzsche: a transvaloração dos valores. São Paulo: Moderna, 1993.

MELO SOBRINHO, N. C. A pedagogia de Nietzsche. In: NIETZSCHE, F. Escritos sobre educação. Tradução de Noéli Correia de Melo Sobrinho. São Paulo: Loyola, 2003. p. 7-39.

NIETZSCHE, F. II Consideração intempestiva: da utilidade e desvantagem da história para a vida. Tradução de Marco Antônio Casanova. Rio de Janeiro: Relume Dumará, 2003a. (Originalmente publicada em 1874).

. III Consideração intempestiva: Schopenhauer educador. In: Escritos sobre educação. Tradução de Noéli Correia de Melo Sobrinho. São Paulo: Loyola, 2003b. (Originalmente publicada em 1874).

. Sobre o futuro de nossos estabelecimentos de ensino. In: Escritos sobre educação. Tradução de Noéli Correia de Melo Sobrinho. São Paulo: Loyola, 2003c. (Originalmente publicada em 1872).

. Assim falava Zaratustra. Tradução de Mário da Silva. Rio de Janeiro: Civilização Brasileira, 1981. (Originalmente publicada em 1885).

. Genealogia da moral. Tradução de Paulo César de Souza. São Paulo: Companhia das Letras, 1998. (Originalmente publicada em 1887).

. O Crepúsculo dos Ídolos ou como Filosofar com o Martelo. Tradução de Paulo César de Souza. São Paulo: Companhia das Letras, 2006. (Originalmente publicada em 1888).

. Para além do Bem e do mal. Tradução de Paulo César de Souza. São Paulo: Companhia das Letras, 2005. (Originalmente publicada em 1886).

. Werke in zwei Band. München: Carl Hanser Verlag, 1954 (I) e 1955 (II).

LÖWITH, K. De Hegel à Nietzsche. Paris: Gallimard, 1969.

NUNES, B. O Nietzsche de Heidegger. São Paulo: Àgora, 2000. 